\title{
COMPORTAMENTO DE VACAS MESTIÇAS HOLANDÊS x ZEBU, EM PASTAGEM DE Brachiaria decumbens EM SISTEMA SILVIPASTORIL ${ }^{1}$
}

Behavior of holstein $\mathrm{x}$ zebu crossbreed cows grazing Brachiaria decumbens in a silvipastoral system

\author{
Tania Mara Soares Paes Leme², Maria de Fátima Ávila Pires ${ }^{3}$, Rui da Silva Verneque ${ }^{3}$, \\ Maurílio José Alvim ${ }^{3}$, Luiz Januário Magalhães Aroeira ${ }^{3}$
}

\begin{abstract}
RESUMO
Estudou-se o comportamento de vacas mestiças Holandês-Zebu, em sistema silvipastoril, avaliando-se o percentual do tempo em que os animais se mantiveram em pé, comendo, ruminando ou em ócio, no verão e no inverno e o tempo em que as vacas se mantiveram ao sol e à sombra e, neste caso, sob qual espécie arbórea. Foram coletados os dados de 32 vacas, em doze dias, seis no inverno e seis no verão, em medidas tomadas a cada 10 minutos, 12 horas por dia (das 6 às 18 h). Os dados foram submetidos à análise de variância e para comparação múltipla entre médias foi usado o teste t de Student, ao nível de 5\% de probabilidade. Verificou-se que, no inverno, os animais preferiram ficar mais ao sol do que à sombra. Já no verão, houve preferência em manterem-se em ambientes sombreados, especialmente sob sombras de espécies arbóreas com copas globosas e densas. Na posição deitada, no inverno, os animais preferiram ficar ao sol e no verão a preferência foi pela sombra. Conclui-se que a procura dos animais por ambientes sombreados, durante o verão, mostra a necessidade da provisão de sombra, para que os mesmos possam viver em ambiente que ofereça conforto térmico.
\end{abstract}

Termos para indexação: Conforto animal, ecologia, pastagem, sombreamento.

\begin{abstract}
The behavior of Holtein $\mathrm{x}$ Zebu crossbreed cows was studied in silvipastoral system, taking in account the time spent by the cows in the stand up position, eating, ruminating or in inactivity, during the summer and winter times. Measures of the time spent by the cows at sunshine and under the shadow was also taken. Data from 32 cows, were collected every ten minutes, 12 hours a day (from 6 A.M. to 6 P.M.), in twelve days, six during the winter and six during the summer times. The data were analyzed through variance system and to multiple comparison among average it was used the test of student, at the level of 5\% of probability. During the winter, cows spent more time at sunshine than in summer time while in the summer the cows remained more time in the shadow mainly under the trees with big and dense crowns. The silvipastoral system should be considered as important tool for animal comfort in the tropical conditions.
\end{abstract}

Index terms: animal comfort, ecology, grazing, shadow.

(Recebido para publicação em 13 de Janeiro de 2003 e aprovado em 4 de fevereiro de 2005)

\section{INTRODUÇÃO}

A baixa adaptação às condições de clima e de manejo, prevalecentes em regiões tropicais, de raças bovinas leiteiras especializadas, selecionadas em regiões temperadas, constitui um dos maiores problemas na produtividade do rebanho em algumas regiões brasileiras. Resultados de pesquisas têm demonstrado que criar animais, em ambiente de conforto e bem-estar, pode refletir diretamente na melhora de seus desempenhos produtivo e reprodutivo. Por isso, minimizar efeitos prejudiciais do clima, sobre os animais, em países de clima tropical e subtropical, tem sido uma constante preocupação dos produtores, visando amenizar a ação danosa das variáveis climáticas consideradas responsáveis pelo estresse calórico.

No verão, a temperatura, a umidade relativa do ar e o calor podem causar desconforto e/ou até mesmo a morte de animais menos adaptados. Calor excessivo, além disso, reduz a ingestão alimentar e aumenta o gasto de energia para manutenção da homeotermia (MADER et al., 1999). Assim, o estresse calórico diminui a produção de leite e a eficiência reprodutiva resultando em baixo desempenho dos animais (ARMSTRONG et al., 1993).

\footnotetext{
1. Parte da tese do primeiro autor, apresentado à Universidade Federal de Juiz de Fora - Departamento de Biologia, para obtenção do título de Mestre em Biologia, na área de Comportamento e Ecologia Animal.

2. Departamento de Biologia da Universidade Federal de Juiz de Fora/UFJF - Rua Ivan Soares de Oliveira, 743 - Parque Imperial - $36.036-350$ Juiz de Fora, MG.

3. Pesquisador(a) da Embrapa Gado de Leite e Bolsista do CNPq.
} 
Esse desconforto pode ser amenizado ou mesmo eliminado pela execução de um programa que resulte no refrescamento dos animais pela provisão de sombra, ventilação e aspersão, instalando-se equipamentos ou utilizando-se de recursos naturais apropriados para redução do estresse calórico.

Alterações de comportamento são realizadas pelo animal com o objetivo de reduzir a produção de calor ou promover a sua perda, evitando estoque adicional de calor corporal. Essas alterações referem-se à mudança do padrão usual de postura, movimentação e ingestão de alimentos. No geral, especialmente no verão, verifica-se que o percentual de vacas comendo durante as horas mais quentes do dia é maior em ambientes sombreados (McDANIEL \& ROARK, 1956; PERERA et al., 1986; SHULTZ, 1983). Tem-se verificado, também, que vacas leiteiras passam menor tempo pastejando no verão e maior tempo no inverno (PIRES et al., 1998; WERNECK, 2001). Por outro lado, no inverno, a porcentagem de vacas ruminando é maior do que no verão (PIRES, 1997; SHULTZ, 1983; WERNECK, 2001) e os animais permanecem maior tempo em ócio durante o verão do que no inverno (PERERA et al., 1986; PIRES, 1997; SHULTZ, 1983). Além disso, procurando aumentar a perda de calor, no verão, as vacas passam maior tempo na posição em pé, ao contrário do inverno, época em que elas preferem ficar deitadas (ARMSTRONG, 1993; PERERA et al., 1986; PIRES et al., 1999, 2001; WERNECK, 2001).

Provisão de sombra é uma das primeiras medidas usadas como modificação do ambiente para proteger o animal do excessivo ganho de calor proveniente da radiação solar e, assim, prevenir o estresse calórico. Tem-se pesquisado uma nova proposta, como alternativa para os sistemas de pastejo tradicionais, que consiste na utilização de sistemas silvipastoris. Estes se caracterizam pelo cultivo de espécies arbóreas em associação com pastagens. As árvores, além de serem cada vez mais necessárias para melhorar a produção, qualidade e a sustentabilidade das pastagens, contribuem para o conforto dos animais, pela provisão de sombra, atenuando as temperaturas extremas, diminuindo o impacto de chuvas e vento, e servindo de abrigo (CARVALHO, 1998).

Os animais procuram selecionar sombras de maior densidade (BENNETT et al., 1985). Segundo a literatura, no inverno a radiação solar não constitui um fator de desconforto para os animais, uma vez que a tendência é dos mesmos preferirem ficar ao sol (BENNETT et al., 1985), com exceção quando estão na posição em pé, ruminando ou em ócio. Ao contrário, quando se compara a porcentagem total do tempo em que os animais utilizaram a sombra no verão e no inverno, verifica-se preferirem a sombra durante a estação quente do ano (PIRES et al., 2001). Por isso, a provisão de sombra pode constituir em elemento essencial para melhorar o conforto dos animais.

Realizou-se este trabalho com o objetivo de avaliar aspectos comportamentais, tais como tempo de pastejo, tempo despendido deitado ou em pé, no sol ou na sombra, de vacas mestiças Holandês-Zebu, mantidas em pastagem de Brachiaria decumbens e em sistema silvipastoril.

\section{MATERIAL E MÉTODOS}

O trabalho foi realizado no Campo Experimental de Coronel Pacheco da Embrapa Gado de Leite, localizado no município de Coronel Pacheco, Estado de Minas Gerais (altitude de 435 metros, latitude de $21^{\circ} 33^{\prime} 22^{\prime \prime}$ Sul e $43^{\circ} 6^{\prime} 15^{\prime \prime}$ Oeste). A classificação do clima é tropical chuvoso, com precipitação anual média de $1533 \mathrm{~mm}$, apresentando amplitude térmica acima de $5^{\circ} \mathrm{C}$, média anual de $19,5^{\circ} \mathrm{C}$, verão chuvoso, inverno seco, nos meses de junho a setembro.

Nos dias de observação foram obtidos os seguintes dados: horários de temperatura ambiente, umidade relativa do ar, do termômetro de globo negro (ao sol e à sombra).

O sistema silvipastoril, no qual foi desenvolvido este estudo, é localizado em área declivosa (aclive suave) e constituído de leguminosas arbóreas distribuídas numa área de pastagem de Brachiaria decumbens de 0,8 ha (piquete), sem a presença de plantas invasoras. As árvores foram plantadas em linhas, com espaçamento de 10 metros entre linhas e entre árvores.

O sistema silvipastoril continha as seguintes espécies arbóreas: Acacia angustissima, Acacia auriculiformis, Acacia mangium, Albizia guachapelle, Albizia lebbek, Anadenanthera sp. (Angico vermelho), Dalbergia nigra (jacarandá da Bahia), Eritrina sp, Gliricidia sepium, Enterolobium contortisiliquum (orelha de macaco), Caesalpinia ferrea (pau ferro), Piptadenia sp. (angico branco), todas constituídas de árvores de médio a grande porte, perenifólias, que forneciam, no máximo, 30\% de sombra ao sistema.

$O$ potencial de produção anual de forragem (matéria seca) da Brachiaria decumbens na área experimental ao sol foi de aproximadamente $13 \mathrm{t} / \mathrm{ha}$, sendo 2,4 t/ha durante o período da seca. Na sombra, o potencial de produção de matéria seca dessa gramínea 
foi próximo de 10 t/ha, sendo 3,5 t/ha durante o período da seca.

Ao longo de alguns anos, anteriores à execução do presente estudo, esse sistema silvipastoril foi manejado de forma que animais entravam no piquete quando a pastagem de Brachiaria decumbens apresentava disponibilidade de forragem próxima de 3 4 t/ha de matéria seca no período das chuvas e de 1,5 a 2 t/ha na época da seca. Essas disponibilidades de forragem correspondiam a altura vegetativa ao redor de 50-60 cm na época das chuvas e 30-35 cm na época da seca. Os animais eram retirados da pastagem quando a disponibilidade de forragem se aproximava de $2 \mathrm{t} / \mathrm{ha}$ na época das chuvas ( $15 \mathrm{~cm}$ de altura) e de $0,5 \mathrm{t} / \mathrm{ha}(10 \mathrm{~cm}$ de altura) na época da seca. Nesses pastejos, adotava-se a taxa de lotação próxima de 16 vacas/ha, no verão, e 8 vacas/ha no inverno.

Durante a época das chuvas, ao sol, a pastagem de Brachiaria decumbens apresentava a condição vegetativa da Brachiaria decumbens com grande proporção de folhas verdes, enquanto que na época da seca predominava maior quantidade de folhas secas, com aspecto de cor amarelada. Sob as árvores, a Brachiaria decumbens mantinha o aspecto vegetativo com boa quantidade de folhas verdes ao longo de todo o ano.

O presente estudo compreendeu quatro fases para tomada dos dados: duas no inverno (junho e julho de 2000) e duas no verão (janeiro e março de 2001). Foram utilizadas, em cada uma das fases, oito vacas, secas, sendo $34 \%$ vazias e $66 \%$ prenhes, mestiças (Holandês x Zebu), com peso médio de $500 \mathrm{~kg}$, e idade média de cinco anos. Para as avaliações, os animais eram colocados no piquete (sem bebedouros e cocho de sal), um dia antes e retirados um dia após cada fase de observação. No momento da entrada dos animais experimentais, as condições vegetativas do sistema silvipastoril correspondiam ao manejo usado anteriormente. Cada fase compreendeu três dias de observação (apenas durante o dia). Os animais eram levados, uma vez ao dia, ao bebedouro situado em piquete adjacente.

Durante os dias de coleta dos dados foram observados os comportamentos dos animais em pastejo, iniciando às $6 \mathrm{~h}$ e finalizando-se às $18 \mathrm{~h}$. As medidas dos padrões comportamentais foram realizadas por colheita instantânea (método "scan-sampling”, SETZ, 1991), a intervalos de 10 minutos, por três observadores que se revezavam e faziam as anotações em planilhas específicas. Por ocasião dessas observações, foi identificado, para cada animal, um dos seguintes comportamentos: posição, se em pé ou deitado; em atividades de alimentação e ruminação ou em ócio. Foi identificado também o local em que cada atividade foi realizada, se sob o sol ou à sombra, e, neste caso, sob qual espécie arbórea.

O ambiente foi monitorado diariamente, usandose termômetros de bulbo seco, bulbo úmido e termômetro de globo negro (aparelho composto de um termômetro dentro de um globo metálico oco, pintado de preto que, colocado à altura do corpo do animal, simula a temperatura ambiente a que ele está submetido). Os termômetros foram mantidos estrategicamente na área, verificados a cada uma hora, para determinarem a temperatura local, a umidade relativa do ar e a radiação solar.

O tempo em que cada animal se manteve exercendo alguma atividade foi transformado em percentual do tempo total de observação por dia. Os dados assim obtidos foram submetido a análise de variância, usando-se o procedimento GLM do SAS (SAS INSTITUTE, 1995) e por análise gráfica, usandose o Excel. O percentual do tempo em que os animais se mantiveram realizando alguma das atividades avaliadas, foi estudado em um modelo estatístico, que inclui os efeitos de época do ano (verão ou inverno), local (se ao sol ou à sombra), posição (se em pé ou deitada) e as interações entre esses efeitos. Foram consideradas significativas as diferenças iguais ou inferiores a $5 \%$ de probabilidade. Para esses casos, as diferenças entre médias foram avaliadas usando-se o teste t de Student.

$$
\begin{aligned}
& y_{i j k}=\mu+e p_{i}+\operatorname{loc}_{j}+\operatorname{pos}_{k}+\left(e p^{*} l o c\right)_{i j}+\left(e p^{*} p o s\right)_{i k}+ \\
& +(l o c * p o s)_{j k}+e_{i j k}
\end{aligned}
$$

em que:

$\mathrm{y}_{\mathrm{ijk}}$ é o percentual do tempo em que o animal se manteve realizando as atividades (comendo ou ruminando), ou em ócio;

$\mu=$ efeito comum a toda observação;

epi efeito da época i, (inverno ou verão);

$\operatorname{loc}_{\mathrm{j}}$ (na sombra ou no sol);

pos $_{\text {i }}$ (em pé ou deitada);

$\mathrm{e}_{\mathrm{ijk}}$ erro aleatório associado a cada observação.

$E$ as demais variáveis são as interações entre os efeitos principais.

\section{RESULTADOS E DISCUSSÃO}

Durante o inverno os animais ficaram mais tempo ao sol $(\mathrm{p}<0,05)$ do que à sombra (Tabela 1$)$. Mas, quando é retirado o tempo em que os animais se mantiveram pastejando (Tabela 2), não se observou 
diferença $(p>0,05)$ entre os locais, indicando que, no inverno, os animais permanecem no ócio ou ruminando tanto ao sol quanto à sombra. Esse resultado comprova que o sol do inverno não é fator estressante para os animais mestiços do padrão genético usado neste trabalho.

Quando se analisam os dados considerando-se apenas o ambiente que os animais buscam para descansar, independente da estação, verifica-se que permaneceram deitados tanto ao sol quanto à sombra
(Tabela 4). Provavelmente, a dispersão das árvores torna o ambiente agradável como um todo, conforme mostram os dados de temperatura do termômetro de globo negro ao sol e à sombra (Tabela 3). Já, na posição em pé, os animais mostraram preferência pela sombra, uma vez que sob as árvores a Brachiaria decumbens mantinha o aspecto vegetativo com boa quantidade de folhas verdes ao longo de todo o ano, tornando-se um atrativo para que os animais permanecessem neste local pastejando.

TABELA 1 - Percentual médio de tempo em que os animais permanecem ao sol e à sombra, por época (erro padrão entre parênteses).

\begin{tabular}{lcl}
\hline \multicolumn{1}{c}{ Época } & Sol (\%) & \multicolumn{1}{c}{ Sombra (\%) } \\
\hline Inverno & $57,5(4,5)^{\mathrm{aA}}$ & $42,6(4,5)^{\mathrm{bB}}$ \\
Verão & $31,4(4,5)^{\mathrm{bB}}$ & $68,6(4,5)^{\mathrm{aA}}$ \\
\hline
\end{tabular}

Na linha, a $>$ b $(\mathrm{p}<0,05)$.

Na coluna, $A>B(p<0,05)$.

TABELA 2 - Percentual médio de tempo em que os animais permanecem ao sol e à sombra, por época, excluindo o tempo em que os animais se mantiveram alimentando (erro padrão entre parênteses).

\begin{tabular}{lcl}
\hline \multicolumn{1}{c}{ Época } & Sol (\%) & Sombra (\%) \\
\hline Inverno & $53,4(7,4)^{\mathrm{aA}}$ & $46,7(7,4)^{\mathrm{aB}}$ \\
Verão & $16,7(7,4)^{\mathrm{bB}}$ & $83,3(7,4)^{\mathrm{aA}}$ \\
\hline
\end{tabular}

Na linha, a $>$ b $(\mathrm{p}<0,05)$.

Na coluna, $A>B(p<0,05)$.

TABELA 3 - Médias de ITU e globo negro, por época, pela manhã e à tarde, observadas no ambiente do experimento nos dias em que foram realizadas as medições do padrão comportamental (erro padrão entre parênteses).

\begin{tabular}{ccccc}
\hline \multirow{2}{*}{ Época } & Período & ITU & \multicolumn{2}{c}{ Globo Negro $\left({ }^{\mathbf{0}} \mathbf{C}\right)$} \\
\cline { 4 - 5 } & & & Sol & Sombra \\
\hline \multirow{2}{*}{ Inverno } & Manhã & $61,3(1,4)$ & $17,9(2,1)$ & $16,9(1,7)$ \\
& Tarde & $70,1(0,3)$ & $30,2(1,2)$ & $26,9(0,6)$ \\
\multirow{2}{*}{ Verão } & Manhã & $72,6(0,8)$ & $29,7(2,1)$ & $26,4(1,7)$ \\
& Tarde & $80,0(0,5)$ & $38,2(1,4)$ & $32,7(0,9)$ \\
\hline
\end{tabular}


TABELA 4 - Percentual médio de tempo dedicado pelos animais à posição, deitada ou em pé, ao sol ou à sombra (erro padrão entre parênteses).

\begin{tabular}{lcl}
\hline \multicolumn{1}{c}{ Posição } & Sol (\%) & Sombra (\%) \\
\hline Deitada & $12,1(2,3)^{\mathrm{aB}}$ & $11,8(2,3)^{\mathrm{aB}}$ \\
Em pé & $32,3(2,3)^{\mathrm{bA}}$ & $43,7(2,3)^{\mathrm{aA}}$ \\
\hline
\end{tabular}

Na linha, $a>b(p<0,05)$.

Na coluna, A $>$ B $(p<0,05)$.

Quando é excluída a porcentagem do tempo gasto no pastejo (Tabela 5), nota-se que não houve redução $(p>0,05)$ no percentual de tempo em que animais se mantiveram ao sol, em pé, quando comparado com a posição deitada. No entanto, à sombra, os animais se mantiveram maior tempo em pé $(\mathrm{p}<0,05)$ do que deitados.

Verificou-se assim, que os animais tendem a se ajustarem ao ambiente térmico alterando sua postura, conforme Pires et al. (1998) e Pough et al. (1993).

Ao analisar a interação entre época, posição e local (Tabela 6), verifica-se que, no inverno, não houve diferença quanto ao local, quando os animais se mantiveram na posição em pé, mostrando que o pastejo, a ruminação e o ócio, nesta posição, são realizados indistintamente, ou seja, tanto ao sol quanto à sombra. No entanto, nesta estação, os animais preferem descansar ao sol, indicando que a radiação solar, provavelmente, não constituí um fator desencadeante do estresse calórico, conforme os dados do globo negro ao sol e à sombra (Tabela 3). Observando estes dados, percebe-se a razão pela qual ser a sombra o local preferido em condições de verão. Nesta época, no período da tarde, houve uma diferença de $6^{0} \mathrm{C}$ na temperatura do globo negro, obtida ao sol e à sombra. Além disso, o índice de temperatura e umidade (ITU) atingiu valor (80) considerado acima do limite (72) (ARMSTRONG, 1993) de conforto térmico para os animais. Esses resultados encontram amplo suporte na literatura (ARMSTRONG, 1993; McDANIEL \& ROARK, 1956; MULLER et al., 1993; PIRES, 1997; PIRES et al., 2001). Com isso, os animais evitam o ganho de calor por radiação.

O tempo despendido pelas vacas, nas atividades enquadradas na categoria de padrão fixo de comportamento (comendo, ruminando e ócio), pode ser observado na Tabela 7. Não houve variação entre épocas ( $>0,05)$, mas houve variação de comportamento.
Houve uma tendência dos animais passarem maior tempo comendo durante o verão do que no inverno. Embora no verão a pastagem estivesse de melhor qualidade e, por isso, se esperasse uma redução no tempo de alimentação, o sistema silvipastoril pode ter fornecido um conforto térmico para os animais e, assim, eles permaneceram maior tempo se alimentando.

Assim, a semelhança no tempo despendido com essas atividades entre as estações do ano (inverno e verão), pode ser devido à presença de árvores que criam um ambiente de conforto para que os animais possam realizar atividades no verão, sem que haja o desconforto destes. Por exemplo, a literatura cita que, no verão há um aumento do tempo despendido em ócio e redução no tempo de ruminação para vacas confinadas em free stall e para vacas em diferentes pastagens (Coast cross, alfafa, capim elefante) (PIRES et al., 2001). A alteração destas duas atividades entre as estações é indicativo de mudança de comportamento para reduzir a produção de calor endógeno numa tentativa de amenizar o estresse calórico (PIRES, 1997). Como essas alterações não foram observadas neste trabalho, reafirma-se a idéia que no verão o sistema silvipastoril propicia um ambiente de conforto térmico para os animais, facilitando a realização de atividades essenciais para a maximização do desempenho em sistemas de produção de leite a pasto.

Independente da época do ano, as espécies preferidas pelos animais, como provedoras de sombra, foram a Acacia mangium, seguida pela Acacia auriculiformis e pela Acacia angustissima (Tabelas 8). Isso ocorreu pela tendência dos animais selecionarem sombra com maior densidade.

A Acacia angustissima foi usada mais no inverno que no verão, e menos usada em detrimento das duas anteriores (Acacia mangium e Acacia auriculiformis), talvez pelo seu porte menor, apesar da copa ampla. 
Essa diferença entre as estações se fez mais marcante quanto ao uso da Albizia guachapele. Os animais demonstraram preferência por árvores de porte mais alto e com copa maior e globosa.

As demais espécies existentes no piquete (Anadenanthera sp., Eritrina sp., Leucaena sp., Enterolobium contortisiliquum, Caesalpinea ferrea, Albizia lebbek, Dalbergia nigra, Gliricidia sepium, Enterologium contortisiliquum e Piptedenia sp) foram usadas, no conjunto, apenas 1,8 e 1,9\% do tempo, no inverno e no verão, respectivamente. Desta forma, decidiu-se apresentar os resultados das mesmas em conjunto.

TABELA 5 - Percentual médio de tempo dedicado pelos animais em posição deitada ou em pé, ao sol ou à sombra, excluindo o tempo em que os animais se mantiveram alimentando (erro padrão entre parênteses).

\begin{tabular}{lcc}
\hline \multicolumn{1}{c}{ Posição } & Sol & Sombra \\
\hline Deitada & $20.4(3,7)^{\mathrm{aA}}$ & $20.4(3,7)^{\mathrm{aB}}$ \\
Em pé & $14.7(3,7)^{\mathrm{bA}}$ & $44.62(3,7)^{\mathrm{aA}}$ \\
\hline
\end{tabular}

Na linha, $a>b(p<0,05)$.

Na coluna, $\mathrm{A}>\mathrm{B}(\mathrm{p}<0,05)$.

TABELA 6 - Percentual médio de tempo dedicado pelos animais em posição deitada ou em pé, ao sol ou à sombra, por época (erro padrão entre parênteses).

\begin{tabular}{lcccc}
\hline & \multicolumn{2}{c}{ Deitada ( \%) } & \multicolumn{2}{c}{ Em pé (\%) } \\
\hline Época & Sol & Sombra & Sol & Sombra \\
Inverno & $19,3(3,2)^{\mathrm{aA}}$ & $6,2(3,2)^{\mathrm{bB}}$ & $38,2(3,2)^{\mathrm{aA}}$ & $36,4(3,2)^{\mathrm{aB}}$ \\
Verão & $5,0(3,2)^{\mathrm{bB}}$ & $17,5(3,2)^{\mathrm{aA}}$ & $26,4(3,2) 7^{\mathrm{bB}}$ & $51,1(3,2)^{\mathrm{aA}}$ \\
\hline
\end{tabular}

Na linha, a $>b(\mathrm{p}<0,05)$.

Na coluna, $\mathrm{A}>\mathrm{B}(\mathrm{p}<0,05)$.

TABELA 7 - Percentual médio de tempo em que os animais permanecem nas atividades, comendo e ruminando, e no ócio, por época.

\begin{tabular}{lccc}
\hline Época & Comendo (\%) & Ruminando (\%) & Ócio (\%) \\
\hline Inverno & 18,9 & 10,0 & 18,3 \\
Verão & 22,4 & 12,0 & 18,3 \\
Média & $20,7^{\text {a }}$ & $11,0^{\mathrm{b}}$ & $18,3^{\mathrm{a}}$ \\
\hline
\end{tabular}

$\mathrm{a}>\mathrm{b}(\mathrm{p}<0,05)$. 
TABELA 8 - Percentual médio de tempo de uso da sombra das árvores pelas vacas, por época (erro padrão entre parênteses).

\begin{tabular}{lcc}
\hline \multicolumn{1}{c}{ Espécie } & Inverno (\%) & Verão (\%) \\
\hline Acacia mangium & $54,9(5,3) \mathrm{aA}$ & $52,4(5,3) \mathrm{aA}$ \\
Acacia auriculiformis & $23,6(5,3) \mathrm{bA}$ & $37,36(5,2) \mathrm{bA}$ \\
Acacia angustissima & $10,4(6,4) \mathrm{bcA}$ & $6,8(5,3) \mathrm{cA}$ \\
Albizia guachapelle & $9,3(9,1) \mathrm{bcA}$ & $1,7(6,4) \mathrm{cB}$ \\
Outras espécies & $1,9(3,4) \mathrm{cA}$ & $1,8(2,0) \mathrm{cA}$ \\
\hline
\end{tabular}

Na linha $\mathrm{A}>\mathrm{B}(\mathrm{p}<0,05)$. Na coluna $\mathrm{a}>\mathrm{b}>\mathrm{c}(\mathrm{p}<0,05)$.

\section{CONCLUSÕES}

O sistema silvipastoril constitui um eficiente método para criação de animais especializados para a produção de leite, fornecendo um ambiente de conforto térmico.

A procura dos animais por ambientes sombreados, durante o verão, mostra a necessidade da provisão de sombra, especialmente usando-se espécies arbóreas com copas globosas e densas, para que os animais possam viver em um ambiente mais favorável.

\section{REFERÊNCIAS BILBLIOGRÁFICAS}

ARMSTRONG, D. V.; WELCHERT, W. T.; WIERSMA, F. Environmental modification for dairy cattle housing in arid climates: livestock environment. Saint Joseph: American Society of Agricultural Engineers, 1993.

BENNETT, I. L.; FINCH, V. A.; HOLMES, C. R. Time spend in shade and its relationship with physiological factors of thermoregulation in three breeds of cattle. Applied Animal Behaviour Science, Amsterdam, v. 13, p. 227-236, 1985.

CARVALHO, M. M. Arborização em pastagens cultivadas. Juiz de Fora: EMBRAPA-CNPGL, 1998. 37 p. (Documentos, 64).

MADER, T. L.; DAHLQUIST, J. M.; HAHN, G. L.; GAUGHAN, J. B. Shade and wind barrier effects on summertime feedlot cattle performance. Journal of Animal Science, Champaign, v. 77, p. 2065-2072, 1999.
McDaniel, A. H.; Roark, C. B. Performance and grazing habitats of Hereford and Aberdeen-Angus cows and calves on improved pastures ad related to types of shade. Journal of Animal Science, Champaign, v. 15, p. 59-63, 1956.

MULLER, C. J. C.; BOTHA, J. A.; SMITH, W. A. Effect of shade on various parameters of Friesian cows in a Mediterranean climate in South Africa: 3. behavior. South Africa Journal of Animal Science, Pretoria, v. 24, p. 61-66, 1993.

PERERA, K. S.; GWADAUSKAS, F. C.; PEARSON, R. E.; BRUMCACK JUNIOR, T. B. Effect of season and stage of lactation on performance of Holstein. Journal Dairy Science, Champaign, v. 69, p. 228-236, 1986.

PIRES, M. F. A. Comportamento, parâmetros fisiológicos e reprodutivos de fêmeas da raça Holandesa confinadas em free stall, durante o verão e inverno. 1997. 151 f. Tese (Doutorado) Universidade Federal de Minas Gerais, Belo Horizonte, 1997.

PIRES, M. F. A.; FERREIRA, A. M. Estresse calórico em bovinos de leite. Cadernos Técnicos de Medicina Veterinária e Zootecnia, [S.I.], n. 29, p. 23-37 ago. 1999.

PIRES, M. F. A.; VILELA, D.;VERNEQUE, R. S.; TEODORO, R. L. Reflexos do estresse térmico no comportamento de vacas em lactalçao. In: SIMPÓSIO BRASILEIRO DE AMBIÊNCIA NA PRODUÇÃO DE LEITE, 1., 1999, Piracicaba. Anais... Piracicaba: [s.n.], 1998. p. 68-99. 
PIRES, M. F. A.; VERNEQUE, R. S.; VILELA, D. Ambiente e comportamento animal na produção do leite. Informe Agropecuário, Belo Horizonte, v. 22, n. 211, p. 11-21, jul./ago. 2001.

POUGH, F. H.; HEISER, J. B.; McFARLAND, W. A vida dos vertebrados. São Paulo: Atheneu, 1993. p. 151-71.

SAS INSTITUTE. SAS user's guide: statistics: version 6. 10. ed. Cary, 1995. 295 p.

SETZ, E. Z. F. Métodos de quantificação de comporta- mento de primatas em estudos de campo. A Primatologia no Brasil, [S.l.], v. 3, p. 411-35, 1991.

SHULTZ, T. A. Weather and shade effects on cow corral activities. Journal of Dairy Science, Champaign, v. 67, p. 868-873, 1983.

WERNECK, C. L. Comportamento alimentar e consumo de vacas em lactação (Holandês-Zebu) em pastagem de capim elefante (Pennisetum purpureum, Sehum.). 2001. 58 f. Dissertação (Mestrado) Universidade Federal de Juiz de Fora, Juiz de Fora, 2001. 